\title{
Study of Diabetic Nephropathy in the Proteomic Era
}

\author{
Visith Thongboonkerd
}

Medical Proteomics Unit, Office for Research and Development, Faculty of Medicine Siriraj Hospital, and Center for Research in Complex Systems Science, Mahidol University, Bangkok, Thailand

\begin{abstract}
Diabetic nephropathy (DN) remains a major complication of diabetes leading to endstage renal disease (ESRD). The number of diabetic patients with ESRD who require renal replacement therapy has been increasing, implicating unsuccessful prevention of diabetic renal complication. This unfavorable outcome reflects insufficient knowledge on pathogenic mechanisms of DN and its detection at late stage. Currently, microalbuminuria is used for diagnosis of DN. However, some patients with microalbuminuria have advanced renal pathological changes indicating that microalbuminuria is not the perfect marker for early detection of DN and a better biomarker is urgently needed. Recently, particularly after the completion of the Human Genome Project, proteomics (systematic analysis of proteins for their identity, quantity and function) has been recognized as an emerging subdiscipline of modern sciences. During the past decade, proteomics has been widely applied to several areas of biomedical research, including the investigation of DN. This chapter summarizes recent progress of proteomics applied to DN with ultimate goals to better understand its pathogenic mechanisms and to search for novel biomarkers for earlier diagnosis.

Copyright $\odot 2011$ S. Karger AG, Basel
\end{abstract}

Despite appropriate treatment, diabetic nephropathy (DN) remains a major complication in diabetic patients and is the leading cause of end-stage renal disease. This unfavorable outcome is most likely due to two main factors. First, the complexity of pathogenic mechanisms of DN is not well understood. Although several previous studies have been conducted to understand this diabetic renal complication, many pieces of the jigsaw of the entire image of its pathogenic mechanisms are still missing. It is not surprising that the prevention of this important diabetic complication is not so successful when this image remains 
hazy. Therefore, better understanding of its pathogenesis and pathophysiology is crucial. Second, detection of DN is problematic. Currently, microalbuminuria is the best noninvasive marker available for the diagnosis of $\mathrm{DN}$ [1]. However, many patients, who were normoalbuminuric and just recently had positive test for microalbuminuria, have advanced renal histopathological changes [2-4], indicating that microalbuminuria is not the perfect marker for early detection of DN. This may be due to a limitation to measure urinary albumin by conventional laboratory method, which is based on an immunoassay that can detect only the immunoreactive forms of albumin, whereas other forms of albumin remain undetectable. Recently, Candiano et al. [5] reported that there are at least 63 forms or fragments of albumin observed in the urine. To be able to detect all forms of albumin and to search for better biomarkers for earlier diagnosis of $\mathrm{DN}$, an unbiased method that can simultaneously detect all forms of proteins is crucially required.

In the postgenomic era, with the completion of the Human Genome Project, several biotechnologies have been developed to utilize the flooding genomic information to explain biology, (patho)physiology, and pathogenic mechanisms of diseases. One of these postgenomic biotechnologies is proteomics (systematic analysis of proteins for their identity, quantity and function [6]), which emerged after the term 'proteome' (set of proteins encoded by the genome) was coined by Marc Wilkins in 1994 [7]. With the success of protein separation science and mass spectrometry, proteomics can be used for simultaneous analyses of a large number of proteins on the genomic scale. Because proteomics can be used for high-throughput screening of proteins that may be involved in biological phenomena and disease pathogenic mechanisms without any need for their specific antibodies, proteomics is considered as an ideal method to examine both immunoreactive and immunounreactive forms of albumin, as well as other proteins in the urine. In addition, this unbiased method is also useful for biomarker discovery and identification of new therapeutic targets. During the past decade, proteomics has been widely applied to several areas of biomedical research, including the investigation of DN. This chapter summarizes recent progress of proteomics applied to DN with ultimate goals to better understand its pathogenic mechanisms and to search for novel biomarkers for earlier diagnosis.

\section{Brief Overview of Proteomic Technologies: Advantages/Disadvantages of Each Technology}

The challenge in proteome analysis is that it involves the complex mixture of proteins, of which physicochemical properties vary and some components are low-abundant proteins. An ideal analytical technique used for proteome analysis should have high resolution, high sensitivity, and high throughput capabilities of protein separation and identification. In the postgenomic biomedical 
Table 1. Advantages and disadvantages of various proteomic methodologies

\begin{tabular}{lll}
\hline Method & Advantages & Disadvantages \\
\hline 2-DE & $\begin{array}{l}\text { available in most of proteomic } \\
\text { labs, simple to perform, practical } \\
\text { for quantitative analysis of } \\
\text { multiple samples }\end{array}$ & $\begin{array}{l}\text { time-consuming, no automation, not } \\
\text { applicable for polypeptides/proteins } \\
\text { with molecular masses }<10 \text { or }>200 \\
\text { kDa, limited use for highly } \\
\text { hydrophobic proteins }\end{array}$ \\
\hline LC-MS/MS & automation, multidimensional, & $\begin{array}{l}\text { time-consuming, quantitative analysis } \\
\text { is not simple, too sensitive towards } \\
\text { high sensitivity }\end{array}$ \\
\hline interfering compounds
\end{tabular}

research, commonly used proteomic technologies include two-dimensional gel electrophoresis (2-DE), liquid chromatography coupled with tandem mass spectrometry (LC-MS/MS), surface-enhanced laser desorption/ionization time-offlight mass spectrometry (SELDI-TOF MS), capillary electrophoresis coupled with mass spectrometry (CE-MS), protein microarrays, and microfluidic technology on a chip. Each of these technologies has its own advantages and disadvantages (table 1). Two-dimensional gel electrophoresis is available in most of proteomic laboratories, is simple to perform, and is practical for quantitative analysis of multiple samples. However, it is time-consuming, not applicable for proteins/peptides with molecular masses $<10$ or $>200 \mathrm{kDa}$, and its utility for highly hydrophobic proteins is still limited $[8,9]$. Liquid chromatography coupled with tandem mass spectrometry can be automated with a high sensitivity. However, it is time-consuming and too sensitive for interfering compounds $[8$, 9]. Moreover, quantitative analysis using LC-MS/MS is not simple and may not 
be applicable in a large sample size. Surface-enhanced laser desorption/ionization time-of-flight mass spectrometry is an easy-to-use system with an automation and high-throughput manner. Only a small volume, such as $<10 \mu \mathrm{l}$, of urine sample is analyzable by SELDI-TOF MS. However, the information obtained from SELDI-TOF MS is restricted only to a particular group of proteins and its reproducibility is still an issue of concern $[8,9]$. Moreover, identification of proteins/peptides from SELDI spectra is not easy. Capillary electrophoresis coupled with mass spectrometry is another sensitive system with a high-throughput mode that requires a small volume of urine sample. However, it is not suitable for analysis of proteins with molecular masses $>20 \mathrm{kDa}[8,9]$. Similar to SELDI-TOF MS, identification of proteins/peptides from CE-MS spectra is not easy. Microarray technology is one of the ideal methods for urinary proteome profiling [10]. This approach allows the high-throughput profiling of multiple proteins in urine samples and offers an opportunity to discover low molecular weight and low abundant biomarkers that may be missed by other (more commonly used) techniques [11]. However, its applications are handicapped by the difficulty to make the arrays to cover all urinary proteins and by the limited availability of antibodies or other ligands [11]. Other limitations include the conservation of protein functionality during immobilization as well as the provision of the required absolute and relative sensitivity [11]. Microfluidic technology on a chip is the latest technology applied to urinary proteome profiling [12]. It is also an easy-to-use system with automation and high throughput. Only $4 \mu \mathrm{l}$ of urine sample is required for analysis by microfluidic technology on a chip. However, the identification of the resolved proteins is still problematic, as in the case of SELDI-TOF MS and CE-MS (table 1).

\section{Proteomic Analysis of Diabetic Nephropathy}

A PubMed search using the keywords 'proteomics' or 'proteomic' or 'proteome' together with 'diabetic nephropathy' retrieved 86 articles published between 2002 and 2010 (fig. 1). This number underscores the great potential of proteomics in the investigation of DN. The following sections summarize some of these recent studies.

Better Understanding of Pathophysiology/Pathogenic Mechanisms of Diabetic Nephropathy by Proteomics Approach

The most commonly used proteomic technique applied to DN is 2-DE, which separates proteins by differential $\mathrm{pH}$ in the first dimension and by differential molecular masses in the second dimension. After spot matching and comparative intensity analysis, spots of interest (differentially expressed spots) are excised and subjected to in-gel tryptic digestion and identification by mass spectrometry (mainly matrix-assisted laser desorption/ionization time-of-flight mass 


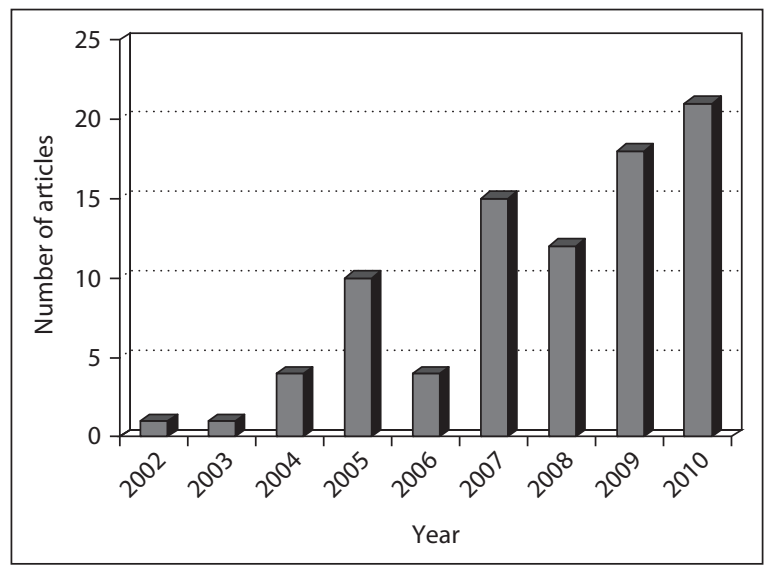

Fig. 1. Number of published articles related to proteomic analysis of DN.

spectrometry or MALDI-TOF MS followed by peptide mass fingerprinting for gel-based proteomic analysis). Thongboonkerd et al. [13] applied a gel-based proteomics approach to examine changes in the renal proteome of OVE26 murine model of type 1 diabetes and observed changes in renal tissue levels of 41 proteins. From these expression data, they focused their attention on the coordinated changes in elastin-elastase pathway. Elastase inhibitor was increased, whereas elastase was decreased. These investigators therefore hypothesized that elastin, which is highly hydrophobic extracellular matrix protein and could not be identified by 2-DE (because of its high hydrophobicity), should be accumulated in diabetic kidney [13]. They then performed immunohistochemical study confirming the hypothesis in both murine and human diabetic kidneys. Elastin was increased in the juxtaglomerular apparatus and renal tubules in the diabetic kidney. This is a good example to demonstrate that proteomics can be used to generate a new hypothesis, which can be confirmed by a conventional method [13].

The same laboratory also identified an increased level of renal calbindinD28k, which is a vitamin-D-dependent calcium-binding protein, in OVE26 diabetic kidney [14]. The increased level of renal calbindin-D28k was confirmed by Western blot analysis. Immunohistochemistry revealed the increase in renal calbindin-D28k predominately in the distal nephron, implicating its role in tubular reabsorption of calcium during $\mathrm{DN}$. These investigators also extended their study to type 2 diabetes using the $d b / d b$ murine model, and found 39 altered renal proteins in this model [15]. Comparing changes identified in both type 1 and type 2 models, it was observed that some proteins had similar changes in both models, which might simply reflect hypoglycemic effects, whereas some other changes were unique in either type 1 or type 2 model, which might be the effects of hypoinsulinemia or hyperinsulinemia 
(insulin resistance). Some proteins had contradictory changes, which might be due to several factors (table 2).

Recently, several other groups also applied gel-based proteomics to DN. Tilton et al. [16] examined changes in renal cortical proteome in $d b / d b$ mice and found alterations in the levels of 147 proteins. These altered proteins play significant roles in several biological processes, particularly in metabolic pathways. The investigators also created an interaction map of all the altered proteins, demonstrating that peroxisome proliferator-activated receptor- $\alpha$ was the common node of these protein-protein interactions. Another study by Ramachandra et al. [17] examined changes in membrane and cytosolic subproteomes in human mesangial cells under high-glucose condition. Four proteins were identified as altered proteins in the membrane fraction, whereas five altered proteins were identified in the cytosolic fraction. Among these altered proteins, calmodulin was identified as one of the increased proteins in the cytosolic fraction. Immunostaining confirmed the increase in calmodulin in mesangial cells exposed to high-glucose environment. Moreover, Western blot analysis confirmed the increase in calmodulin not only in high-glucose-exposed mesangial cells but also in rat and mouse diabetic kidney tissues. To address functional significance of calmodulin in diabetic kidney, these investigators examined effect of calmodulin inhibition on glucose uptake in mesangial cells. Functional analysis revealed that inhibition of calmodulin activity by two compounds, W7 and trifluoperazine, completely abolished transforming growth factor- $\beta$ induced glucose uptake in mesangial cells. These data indicate that calmodulin plays significant role in glucose transport in mesangial cells [17]. More recently, a similar study was performed by Li et al. [18] to identify changes in cellular proteome of rat mesangial cells upon exposure to high-glucose culture medium. Using 2-DE followed by MALDI-TOF MS, the investigators identified 28 proteins with altered levels in high-glucose condition. Among these, the reduction in proteasome subunit-a type 6 was confirmed not only in rat mesangial cells under the high-glucose condition, but also in streptozotocin-induced diabetic rats and spontaneous OLETF diabetic rat model.

\section{Biomarker Discovery in Diabetic Nephropathy Using Proteomics Approach}

An attempt to find urinary biomarkers for DN (and other glomerular diseases such as focal segmental glomerulosclerosis, lupus nephritis class IV, and membranous nephropathy) was made by Varghese et al. [19]. They found no single biomarker could differentiate type or cause of glomerular diseases. However, they used an artificial neural network to create a prediction algorithm and to define disease-specific urinary proteome profile or molecular signature containing multiple markers that could differentiate types of the diseases. They successfully defined such molecular signature containing 21 proteins, which provided a sensitivity of $75-86 \%$ and a specificity of $67-92 \%$ for the differentiation in a validation set of samples. 
Table 2. Comparisons of changes in renal proteome between type 1 and type 2 diabetes

\begin{tabular}{|c|c|c|c|}
\hline \multirow[t]{2}{*}{ Altered renal proteins } & \multicolumn{2}{|c|}{ Changes in renal tissue } & \multirow[t]{2}{*}{ Hypothesis } \\
\hline & type 1 & type 2 & \\
\hline $\begin{array}{l}\text { Antithrombin-III } \\
\text { Calbindin } \\
\text { Calmodulin } \\
\text { Complement component 1, q } \\
\text { subcomponent-binding protein } \\
\text { Myosin, light chain, smooth muscle } \\
\text { Elastase inhibitor } \\
\text { T-kininogen }\end{array}$ & $\begin{array}{l}\text { increased } \\
\text { increased } \\
\text { increased } \\
\text { increased }\end{array}$ & $\begin{array}{l}\text { increased } \\
\text { increased } \\
\text { increased } \\
\text { increased }\end{array}$ & hyperglycemic effects \\
\hline $\begin{array}{l}\text { Apolipoprotein A-IV precursor } \\
\text { Cellular retinol-binding protein } \\
\text { Contraception-associated protein } 1 \\
\text { Crocalbin-like protein } \\
\text { Cytoskeletal tropomyosin } \\
\text { Deoxyribonuclease I } \\
\text { Elastase } \\
\text { Ferritin heavy chain } \\
\text { Ferritin heavy chain } \\
\text { Hippocampal cholinergic } \\
\text { neurostimulating peptide precursor } \\
\text { Histone H3.2 } \\
\text { HSPC207 } \\
\text { Na-H exchanger, isoform } 3 \text { regulator } 1 \\
\text { Skeletal muscle tropomyosin } \\
\text { Vimentin }\end{array}$ & $\begin{array}{l}\text { increased } \\
\text { increased } \\
\text { increased } \\
\text { increased } \\
\text { increased } \\
\text { increased } \\
\text { decreased } \\
\text { increased } \\
\text { increased } \\
\text { increased } \\
\text { increased } \\
\text { increased } \\
\text { increased } \\
\text { increased } \\
\text { increased }\end{array}$ & $\begin{array}{l}\text { unchanged } \\
\text { unchanged } \\
\text { unchanged } \\
\text { unchanged } \\
\text { unchanged } \\
\text { unchanged } \\
\text { unchanged } \\
\text { unchanged } \\
\text { unchanged } \\
\text { unchanged } \\
\text { unchanged } \\
\text { unchanged } \\
\text { unchanged } \\
\text { unchanged } \\
\text { unchanged }\end{array}$ & hypoinsulinemic effects \\
\hline $\begin{array}{l}\text { A1AT } \\
\text { Antithrombin-III } \\
\text { Antithrombin-III } \\
\text { Antithrombin-III } \\
\text { Antithrombin-III } \\
\text { ATP synthase delta chain, mitochondrial } \\
\text { precursor } \\
\text { Nucleobindin } \\
\text { Serine protease inhibitor } 1-1\end{array}$ & $\begin{array}{l}\text { unchanged } \\
\text { unchanged } \\
\text { unchanged } \\
\text { unchanged } \\
\text { unchanged } \\
\text { unchanged } \\
\text { unchanged } \\
\text { unchanged }\end{array}$ & $\begin{array}{l}\text { decreased } \\
\text { increased } \\
\text { increased } \\
\text { increased } \\
\text { increased } \\
\text { increased } \\
\text { decreased } \\
\text { decreased }\end{array}$ & $\begin{array}{l}\text { hyperinsulinemic effects } \\
\text { (or effects from insulin } \\
\text { resistance) }\end{array}$ \\
\hline $\begin{array}{l}\text { Ferritin light chain } 1 \\
\text { Phosphatidylethanolamine-binding protein }\end{array}$ & $\begin{array}{l}\text { increased } \\
\text { decreased }\end{array}$ & $\begin{array}{l}\text { decreased } \\
\text { increased }\end{array}$ & multifactorial \\
\hline
\end{tabular}


Biomarkers were also searched in serum using gel-based proteomics approach. Kim et al. [20] compared serum proteome profile of type 2 diabetic patients with microalbuminuria or end-stage renal disease to normoalbuminuric patients. They found changes in serum levels of 26 proteins in the two groups with renal involvement compared to normoalbuminuric patients. Some of the changes were confirmed by Western blot analysis, e.g. the decrease in extracellular glutathione peroxidase and apolipoprotein E. They also verified their results in a larger, independent set of samples, which clearly confirmed the decrease in glutathione peroxidase in diabetic patients with renal involvement.

Sharma et al. [21] applied gel-based proteomics to DN, but with another technique, the so-called difference in-gel electrophoresis, to find differentially excreted proteins in the urine. Basically, two groups of samples labeled with different dyes were run together within the same gel to avoid gel-to-gel variability. Using this technique, they identified 63 differentially excreted proteins in the urine of patients with long-standing diabetes, impaired renal function and overt proteinuria compared to the controls. One of these differentially excreted proteins was identified by mass spectrometry as $\alpha_{1}$-antitrypsin (A1AT). ELISA clearly confirmed the marked increase in A1AT in the urine obtained from diabetic patients. Moreover, immunohistochemical study also revealed the increased tissue expression of A1AT in the diabetic kidney.

Subsequent difference in-gel electrophoresis study by Rao et al. [22] compared the normal urine with that obtained from type 2 diabetic patients with normoalbuminuria, microalbuminuria and macroalbuminuria. Using this technique, they successfully identified several proteins, which had differential levels among the four groups. Interestingly, they found a group of proteins with progressive changes in association with the degree of proteinuria. Surprisingly, they observed the decrease in urinary A1AT in diabetic patients, in contrast to the findings reported by Sharma et al. [21] as discussed above. As A1AT has multiple forms or fragments in the urine, these disparate results might reflect differential forms detected in these two studies.

Capillary electrophoresis coupled with mass spectrometry is another powerful tool for proteome profiling. The system contains capillary loops and electrospray ionization-TOF mass spectrometer. The specific software is used for analyzing the peptide signals and profiles. CE-MS was utilized by Meier et al. [23] to differentiate urinary polypeptide profiles of patients with type 1 diabetes from those of age-matched healthy controls. The analysis revealed that urinary polypeptide pattern of patients with diabetes significantly differed from that of the normal controls. They also performed subgroup analysis and found a pattern of potential biomarkers that could differentiate patients with DN from those without nephropathy. The same group also employed CE-MS to differentiate urinary polypeptide profiles of patients with type 2 diabetes from those of age-matched healthy controls [24]. In the latter study, they also observed specific urinary polypeptide profile for each subgroup based upon the degree of albuminuria. 
Surface-enhanced laser desorption/ionization time-of-flight mass spectrometry or ProteinChip technology is widely used for examination of human body fluids. Protein sample is applied onto a chip surface carrying a functional group. After incubation, proteins that do not bind to the surface are removed, and the bound polypeptides or proteins are analyzed by TOF mass spectrometer. Recently, Cho et al. [25] utilized SELDI-TOF MS to search for potential biomarkers in the sera of streptozotocin-induced diabetic rats compared to control animals. They observed eight potential biomarkers in the serum, one of which was identified as C-reactive protein. The increased serum level of C-reactive protein was confirmed by ELISA.

In another study, Dihazi et al. [26] performed SELDI proteome profiling of urine samples obtained from type 2 diabetic patients with nephropathy, compared to those without nephropathy, proteinuric patients from nondiabetic causes, and healthy controls. They identified three protein spectra with mass/ charge (or $\mathrm{m} / \mathrm{z}$ ) of $6,188,11,744$, and 14,766 that were differentially excreted among groups. Interestingly, these three spectra could differentiate diabetic patients with nephropathy from those without nephropathy. Subsequently, these SELDI spectra were identified by mass spectrometry as ubiquitin, $\beta_{2^{-}}$ microglobulin, and UbA52 ubiquitin ribosomal fusion protein, respectively. Therefore, these proteins may serve as potential biomarkers for the diagnosis of DN. These data were consistent with the findings reported in a subsequent similar study by Papale et al. [27], in which ubiquitin and $\beta_{2}$-microglobulin were identified as potential biomarkers of DN after initial SELDI profiling in a larger number of type 2 diabetic patients.

Additionally, Otu et al. [28] conducted a SELDI study of baseline urine samples collected from Pima Indians with type 2 diabetes 10 years before microalbuminuria occurred. A comparison with those who remained normoalbuminuric after 10 years in the first sample collection, revealed a molecular signature containing 12 SELDI spectra that could differentiate patients who subsequently developed DN from those who remained normoalbuminuric. This is a good work that yielded significant data to predict DN in a long-term follow-up study.

The recent advanced technology applied to urinary proteomics is a microfluidic technology on a chip [29]. Only $4 \mu \mathrm{l}$ of the untreated urine could be analyzed by this system. Thongboonkerd et al. [29] employed this system to define disease-specific urinary biomarkers for DN and IgA nephropathy. By multiple comparisons, there were significant differences between the normal and diseased urine, and between $\mathrm{DN}$ and IgA nephropathy. There were three protein spectra or bands at approximately $12-15,27-28$ and $34-35 \mathrm{kDa}$ that could distinguish DN from IgA nephropathy. Therefore, these differences may serve as the disease-specific biomarkers.

More recently, Merchant et al. [30] differentiated peptidome profiles of patients with type 1 diabetes with microalbuminuria who had normal renal function from those of patients who had declined renal function. Using LC- 
MALDI-TOF MS profiling, they identified three peptides that were decreased [including fragments of collagen $\alpha_{1}(I V)$ and $\alpha_{1}(V)$ and tenascin-X] and three peptides that were increased (fragments of inositol polyphosphate 2-kinase, zona occludens 3, and FAT tumor suppressor 2) in the urine of patients with declined renal function. Immunohistochemical study also revealed the increased expression levels of tissue polyphosphate 2-kinase and zona occludens 3, consistent with the urinary peptidome data. These peptides may serve as the predictors of DN progression.

\section{Conclusion}

Since 2002, proteomics has played a significant role in the study of DN to address its pathophysiology/pathogenic mechanisms and to search for novel biomarkers for its earlier diagnosis. From these proteomic studies, several datasets have been reported to better understand pathophysiology/pathogenic mechanisms of $\mathrm{DN}$, and a large number of biomarker candidates for diagnosis and prediction of DN have been identified. However, the information obtained from these studies remains on bench and is currently not closed to clinical application. To achieve the ultimate goal of clinical application, validation of the proteomic data in a larger sample size with appropriate control groups (i.e. other kidney diseases with similar clinical presentations and laboratory findings that mimic $\mathrm{DN}$ ) is crucial. Although an attempt has been made in Europe to validate proteomic biomarkers in the urine of patients with DN, this multicenter study [31] limited its scope only to CE-MS data. There should be broader application of the data generated by other proteomic technologies as well. More importantly, translation of all these data to the ready and easy-to-use diagnostic kit(s) is needed. Even with some degree of progression in proteomics applied to DN, the total number of 86 articles published during 2002-2010 is much fewer than anticipated. Urgent attention is required to promote proteomic investigations of DN. It is envisaged that within the next 5-10 years proteomics will be more extensively applied to DN to unravel the complexity of its pathophysiology/ pathogenic mechanisms and to define novel biomarkers for more accurate and earlier diagnosis as well as prognosis of DN. Thereafter, bedside application of proteomic data to diabetic patients will be achievable.

\section{Acknowledgements}

This work was supported by Office of the Higher Education Commission and Mahidol University under the National Research Universities Initiative, and The Thailand Research Fund (RTA5380005). 


\section{References}

1 Caramori ML, Fioretto P, Mauer M: The need for early predictors of diabetic nephropathy risk: is albumin excretion rate sufficient? Diabetes 2000;49:1399-1408.

-2 Chavers BM, Bilous RW, Ellis EN, Steffes MW, Mauer SM: Glomerular lesions and urinary albumin excretion in type I diabetes without overt proteinuria. N Engl J Med 1989;320:966-970.

3 Fioretto P, Steffes MW, Mauer M: Glomerular structure in nonproteinuric IDDM patients with various levels of albuminuria. Diabetes 1994;43:1358-1364.

-4 Bangstad HJ, Osterby R, Dahl-Jorgensen K, Berg KJ, Hartmann A, Nyberg G, Frahm BS, Hanssen KF: Early glomerulopathy is present in young, type 1 (insulin-dependent) diabetic patients with microalbuminuria. Diabetologia 1993;36:523-529.

5 Candiano G, Musante L, Bruschi M, Petretto A, Santucci L, Del Boccio P, Pavone B, Perfumo F, Urbani A, Scolari F, Ghiggeri GM: Repetitive fragmentation products of albumin and alpha1-antitrypsin in glomerular diseases associated with nephrotic syndrome. J Am Soc Nephrol 2006;17:3139-3148.

6 Peng J, Gygi SP: Proteomics: the move to mixtures. J Mass Spectrom 2001;36: 1083-1091.

7 Wilkins MR, Sanchez JC, Gooley AA, Appel RD, Humphery-Smith I, Hochstrasser DF, Williams KL: Progress with proteome projects: why all proteins expressed by a genome should be identified and how to do it. Biotechnol Genet Eng Rev 1996;13:19-50.

$>8$ Fliser D, Novak J, Thongboonkerd V, Argiles A, Jankowski V, Girolami MA, Jankowski J, Mischak H: Advances in urinary proteome analysis and biomarker discovery. J Am Soc Nephrol 2007;18:1057-1071.

-9 Thongboonkerd V: Recent progress in urinary proteomics. Proteomics Clin Appl 2007;1:780-791.

10 Liu BC, Zhang L, Lv LL, Wang YL, Liu DG, Zhang XL: Application of antibody array technology in the analysis of urinary cytokine profiles in patients with chronic kidney disease. Am J Nephrol 2006;26:483490.
11 Angenendt P: Progress in protein and antibody microarray technology. Drug Discov Today 2005;10:503-511.

12 Thongboonkerd V, Songtawee N, Sritippayawan S: Urinary proteome profiling using microfluidic technology on a chip. J Proteome Res 2007;6:2011-2018.

13 Thongboonkerd V, Barati MT, McLeish KR, Benarafa C, Remold-O’Donnell E, Zheng S, Rovin BH, Pierce WM, Epstein PN, Klein JB: Alterations in the renal elastin-elastase system in type 1 diabetic nephropathy identified by proteomic analysis. J Am Soc Nephrol 2004;15:650-662.

14 Thongboonkerd V, Zheng S, McLeish KR, Epstein PN, Klein JB: Proteomic identification and immunolocalization of increased renal calbindin-D28k expression in OVE26 diabetic mice. Rev Diab Stud 2005;2:17-24.

15 Thongboonkerd V, Barati MT, McLeish KR, Rovin BH, Pierce WM, Epstein PN, Klein JB: Altered elastase inhibitor and elastin expression in type 2 diabetic kidneys defined by proteomic analysis. J Am Soc Nephrol 2003;14 (suppl):600A.

16 Tilton RG, Haidacher SJ, Lejeune WS, Zhang X, Zhao Y, Kurosky A, Brasier AR, Denner L: Diabetes-induced changes in the renal cortical proteome assessed with two-dimensional gel electrophoresis and mass spectrometry. Proteomics 2007;7:1729-1742.

17 Ramachandra Rao SP, Wassell R, Shaw MA, Sharma K: Profiling of human mesangial cell subproteomes reveals a role for calmodulin in glucose uptake. Am J Physiol Renal Physiol 2007;292:F1182-F1189.

18 Li Z, Zhang H, Dong X, Burczynski FJ, Choy P, Yang F, Liu H, Li P, Gong Y: Proteomic profile of primary isolated rat mesangial cells in high-glucose culture condition and decreased expression of PSMA6 in renal cortex of diabetic rats. Biochem Cell Biol 2010;88:635-648.

19 Varghese SA, Powell TB, Budisavljevic MN, Oates JC, Raymond JR, Almeida JS, Arthur JM: Urine biomarkers predict the cause of glomerular disease. J Am Soc Nephrol 2007;18:913-922. 
20 Kim HJ, Cho EH, Yoo JH, Kim PK, Shin JS, Kim MR, Kim CW: Proteome analysis of serum from type 2 diabetics with nephropathy. J Proteome Res 2007;6:735-743.

21 Sharma K, Lee S, Han S, Lee S, Francos B, McCue P, Wassell R, Shaw MA, RamachandraRao SP: Two-dimensional fluorescence difference gel electrophoresis analysis of the urine proteome in human diabetic nephropathy. Proteomics 2005;5:2648-2655.

-22 Rao PV, Lu X, Standley M, Pattee P, Neelima G, Girisesh G, Dakshinamurthy KV, Roberts CT Jr, Nagalla SR: Proteomic identification of urinary biomarkers of diabetic nephropathy. Diabetes Care 2007;30:629-637.

23 Meier M, Kaiser T, Herrmann A, Knueppel S, Hillmann M, Koester P, Danne T, Haller $\mathrm{H}$, Fliser D, Mischak H: Identification of urinary protein pattern in type 1 diabetic adolescents with early diabetic nephropathy by a novel combined proteome analysis. J Diabetes Complications 2005;19:223-232.

24 Mischak H, Kaiser T, Walden M, Hillmann M, Wittke S, Herrmann A, Knueppel S, Haller H, Fliser D: Proteomic analysis for the assessment of diabetic renal damage in humans. Clin Sci (Lond) 2004;107:485-495.

25 Cho WC, Yip TT, Chung WS, Leung AW, Cheng $\mathrm{CH}$, Yue KK: Differential expression of proteins in kidney, eye, aorta, and serum of diabetic and non-diabetic rats. J Cell Biochem 2006;99:256-268.

26 Dihazi H, Muller GA, Lindner S, Meyer M, Asif AR, Oellerich M, Strutz F:

Characterization of diabetic nephropathy by urinary proteomic analysis: identification of a processed ubiquitin form as a differentially excreted protein in diabetic nephropathy patients. Clin Chem 2007;53:1636-1645.
27 Papale M, Di Paolo S, Magistroni R, Lamacchia O, Di Palma AM, De Mattia A, Rocchetti MT, Furci L, Pasquali S, De Cosmo S, Cignarelli M, Gesualdo L: Urine proteome analysis may allow noninvasive differential diagnosis of diabetic nephropathy. Diabetes Care 2010;33:2409-2415.

28 Otu HH, Can H, Spentzos D, Nelson RG, Hanson RL, Looker HC, Knowler WC, Monroy M, Libermann TA, Karumanchi SA, Thadhani R: Prediction of diabetic nephropathy using urine proteomic profiling 10 years prior to development of nephropathy. Diabetes Care 2007;30:638-643.

29 Thongboonkerd V, Songtawee N, Sritippayawan S: Urinary proteome profiling using microfluidic technology on a chip. J Proteome Res 2007;6:2011-2018.

30 Merchant ML, Perkins BA, Boratyn GM, Ficociello LH, Wilkey DW, Barati MT, Bertram CC, Page GP, Rovin BH, Warram JH, Krolewski AS, Klein JB: Urinary peptidome may predict renal function decline in type 1 diabetes and microalbuminuria. J Am Soc Nephrol 2009;20:2065-2074.

31 Alkhalaf A, Zurbig P, Bakker SJ, Bilo HJ, Cerna M, Fischer C, Fuchs S, Janssen B, Medek K, Mischak H, Roob JM, Rossing K, Rossing P, Rychlik I, Sourij H, Tiran B, Winklhofer-Roob BM, Navis GJ: Multicentric validation of proteomic biomarkers in urine specific for diabetic nephropathy. PLoS One 2010;5:e13421.

Visith Thongboonkerd, MD, FRCPT

Medical Proteomics Unit, Office for Research and Development, Faculty of Medicine Siriraj Hospital, and Center for Research in Complex Systems Science, Mahidol University

12th Floor Adulyadej Vikrom Building, 2 Prannok Road

Bangkoknoi, Bangkok 10700 (Thailand)

Tel./Fax +66 2 4184793, E-Mail thongboonkerd@dr.com 